\title{
Experimentally validated dynamic model for a hybrid cascade system for solar heating and cooling applications
}

\author{
Valeria Palomba', Andrea Frazzica ${ }^{1}$, Steffen Kühnert ${ }^{2}$, André Große ${ }^{2}$ \\ ${ }^{1}$ Istituto di Tecnologie Avanzate per l'Energia CNR-ITAE, Messina (Italy) \\ 2 Fahrenheit GmbH, Halle (Germany)
}

\begin{abstract}
This paper presents the dynamic modelling of a hybrid cascade chiller for solar cooling in industrial applications driven by Fresnel solar thermal collectors. The chiller comprises an adsorption module, which is directly connected to the bottoming vapor compression chiller. This cascade configuration allows enhancing the overall electric COP, since the adsorption module is operated to dissipate the heat rejected by the vapor compression chiller, thus reducing the condensation temperature quite below the ambient temperature. The model was implemented in Dymola/Modelica, allowing describing heat and mass transfer phenomena inside each component. The complete model was then validated against experimental data obtained on a cascade chiller prototype at the CNR ITAE lab. Finally, a reference daily simulation was performed to evaluate the ability of the developed chiller in providing cooling energy to a typical industrial application.
\end{abstract}

Keywords: Dymola/Modelica, cascade chiller, industrial solar cooling

\section{Introduction}

The cooling demand is continuously growing worldwide in different sectors (Werner, 2016). Particularly, energy consumption and related emissions due to cooling processes in industrial sector are becoming a major issue. For this reason, the integration of renewable thermal energy sources inside industrial sites, for both heating and cooling applications is gaining a lot of attention (Farjana et al., 2018). Usually, it is accomplished with the use of thermally driven sorption machine, driven by thermal energy produced by non-concentrating solar thermal collectors (e.g. flat plate, evacuated tubes) (Murray et al., 2016). Nevertheless, this approach suffers of some weaknesses: first, when renewable source (i.e. solar energy) is not available, a backup system is needed to either operate the sorption chiller (e.g. gas boiler) or to directly produce cooling by means of standard technology (e.g. vapour compression chiller). Secondly, the use of non-concentrating solar thermal collectors technologies often is not sufficient to properly drive the sorption machine, thus making it work under off-design conditions for several hours. Furthermore, these solar thermal collectors cannot be integrated as heating source in most of the industrial sites, since the achievable temperature level is usually not sufficient drive any process.

In such a background, the EU co-funded project HyCool (HyCool, 2018) aims at increasing the use of solar heat in industrial processes, integrating a concentrating Fresnel solar thermal collector technology, with a hybrid cascade chiller, to increase the share of renewable sources for heating and cooling applications in industries.

The present paper deals with the development of a numerical model, implemented in Dymola/Modelica, for the simulation of the innovative cascade chiller. The model describe heat and mass transfer phenomena in each component of the chiller, in order to accurately simulate its operation. Furthermore, it has been validated by means of experimental data measured at the CNR ITAE lab and it will be further used to evaluate optimal operating conditions and management strategies under typical working boundaries of an industrial plant.

\section{The Hybrid cascade chiller}

The hybrid heat pump is made up of two units, working in cascade mode: a thermal unit and an electric unit. The thermal unit is an adsorption chiller, based on the system already commercialised by Fahrenheit, which will be driven by the heat produced by a field of Fresnel solar thermal collectors, for the production of chilled water in the range of $16-22^{\circ} \mathrm{C}$. This unit is hydraulically connected to the condenser of an electric vapour compression unit (i.e. cascading mode), which will provide chilled water to the user. In such a way, the adsorption unit is primarily meant for dissipating the condensation heat of the vapour compression unit. This operation allows increasing the overall electric COP, by reducing the temperature lift between evaporator and condenser of the vapour compression unit, 
thus limiting the compressor work.

Furthermore, the utilization of the cascading operation of the two units allows exploiting the benefits of the two types of systems, i.e. the low primary energy consumption of the thermal unit, which will be fed by renewable solar energy, and the fast response and good temperature control under different conditions of the electric unit (Vasta et al., 2018). A schematic of the hybrid heat pump operation and components as well as the different temperature levels is reported in Figure 1.

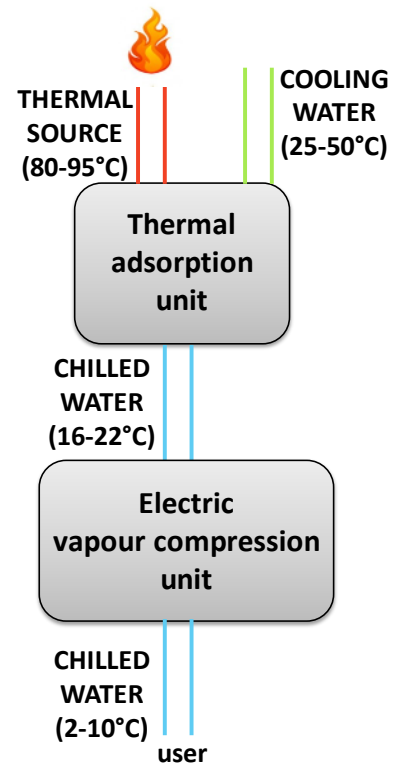

Figure 1: schematic layout of the hybrid heat pump.

\section{Dynamic modeling and validation}

As shown in Figure 1, the hybrid heat pump is realized by hydraulically connecting the thermal and electric units. Consequently, the models for the two units were implemented and tested separately and then the overall model for the system was assembled and calibrated.

\subsection{Model of the adsorption unit}

The thermal adsorption unit implemented in Dymola is composed of four main vacuum vessels: two adsorbers, a condenser and an evaporator, as represented in Figure 2. Furthermore, the hydraulics and valves are included to properly operate the system.

The structure of each modelled components (i.e. adsorber, evaporator and condenser) is similar. Indeed, each of them is composed of two sub-models: one describing the heat transfer on the heat transfer fluid (HTF) side, and the other one representing an equilibrium model, describing heat and mass transfer for the refrigerant (Lanzerath et al., 2015).

The following assumptions were made:

- all components are lumped models with uniform properties;

- the HTF inside the heat exchangers is incompressible;

- pressure drops inside the heat exchangers and the hydraulic circuit are constant;

- gravity is neglected;

- the thermal masses of vacuum vessels is neglected;

- there are no heat losses to the environment;

- there is no direct heat exchange due to conduction between the components;

- there are no inert gases inside the system.

The heat transfer model is based on a mono-dimensional fluid flow from Thermocycle library (Quoilin et al., 2014). It implements mass and energy balance on the HTF fluid side, in which all the thermodynamic properties of the HTF 
are calculated on the basis of its state variables, taken from the Modelica Fluid library.

The heat transfer on the fluid side is calculated as:

$$
\dot{Q}_{\text {wall }}=\alpha S\left(T_{\text {fluid }}-T_{\text {wall }}\right)
$$

Where the heat transfer coefficient $\alpha\left[\mathrm{W} \mathrm{m}^{-2} \mathrm{~K}^{-1}\right]$ takes into account both the convection inside the tubes of the heat exchanger and the thermal conduction through the wall.

The model for adsorption results from the energy conservation inside the adsorber and mass exchange with the condenser/evaporator. Energy conservation is expressed as:

$$
\left(m_{\text {sorb }} c_{p_{\text {sorb }}}+w \cdot m_{\text {sorb }} c_{p_{\text {ref }}}\right) \frac{d T_{\text {sorb }}}{d t}=\dot{Q}+\dot{m}_{\text {ref }} h_{\text {ads }}-m_{\text {sorb }} c_{p_{\text {sorb }}} T_{\text {sorb }} \frac{d w}{d t}
$$

Where, the left-hand side represents the heat stored in the adsorbent, whereas the right-hand side represents the heat transferred through conduction and the mass exchange. The heat of adsorption was considered constant and equal to $2600 \mathrm{~J} \mathrm{~kg}^{-1}$, which is a reliable approximation for the microporous silica gel (i.e. Oker Chemie Siogel ${ }^{\circledR}$ ) used in the tested chiller, as reported in (Bales et al., 2005). The equilibrium data of the adsorbent material are evaluated according to the Dubinin-Astakhov approach (Dubinin and Astakhov, 1971), reporting the uptake as a function of the adsorption potential $\mathrm{A}\left[\mathrm{J} \mathrm{kg}^{-1}\right]$, as reported below:

$$
w=w_{0} \exp (-b A)
$$

Where, $\mathrm{w}\left[\mathrm{kg} \mathrm{kg}^{-1}\right]$ is the adsorption uptake, $\mathrm{w}_{0}\left[\mathrm{~kg} \mathrm{~kg}^{-1}\right]$ is the maximum adsorption uptake at water vapour saturation condition, and $\mathrm{b}\left[\mathrm{kg} \mathrm{J}^{-1}\right]$ is a fitting parameter. The data reported in (Sapienza et al., 2017) were used for characterizing the adsorbent material.

The adsorption kinetic was implemented using the Linear Driving Force (LDF) approach (El-Sharkawy, 2011), where the rate of adsorption/desorption is directly related to the difference between equilibrium and actual adsorption uptake as reported below, as well as to the silica gel grain size and to the diffusion coefficient $\mathrm{D}\left[\mathrm{m}^{2} \mathrm{~s}^{-1}\right]$ (Lanzerath et al., 2015):

$$
\frac{d w}{d t}=\frac{15 m_{\text {sorb }}}{r_{\text {sorb }}^{2}} D\left(w_{\text {eq }}-w\right)
$$

The refrigerant equilibrium model, for evaporator and condenser, consists of mass and energy balance equations, where the properties in liquid and vapour state, as well as in saturation conditions, are calculated from the Modelica Fluid library.

Finally, the vacuum valves are assumed to be two-way valves, characterized by a constant pressure-drop. The valves can be operated either according to the pressure difference between adsorbe and evaporator/condenser or on a time basis, considering the phase of the cycle.

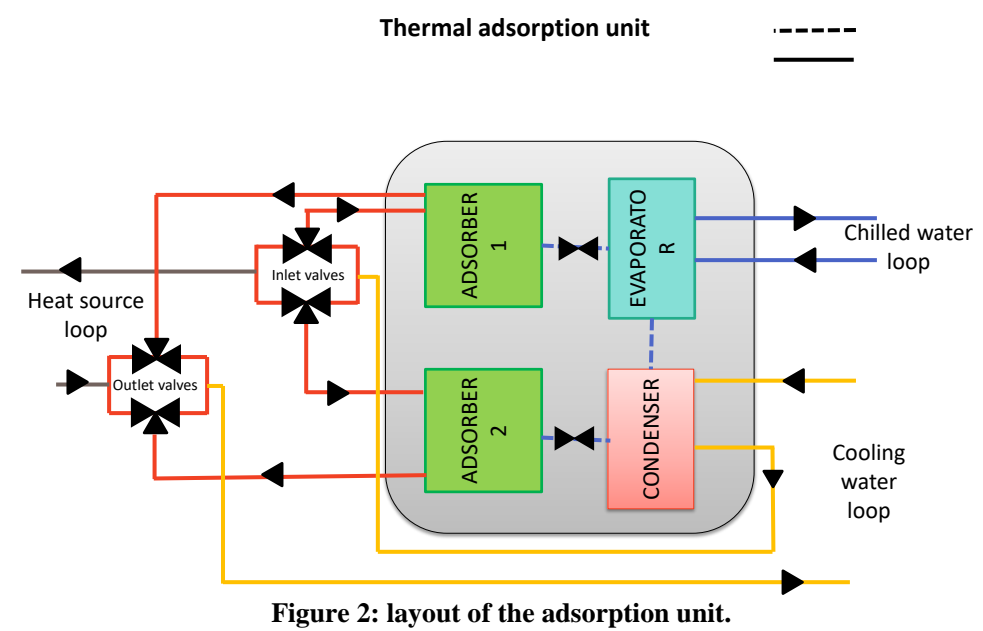

The overall adsorption module, comprising each component as well as the hydraulics, is represented in Figure 3 . 


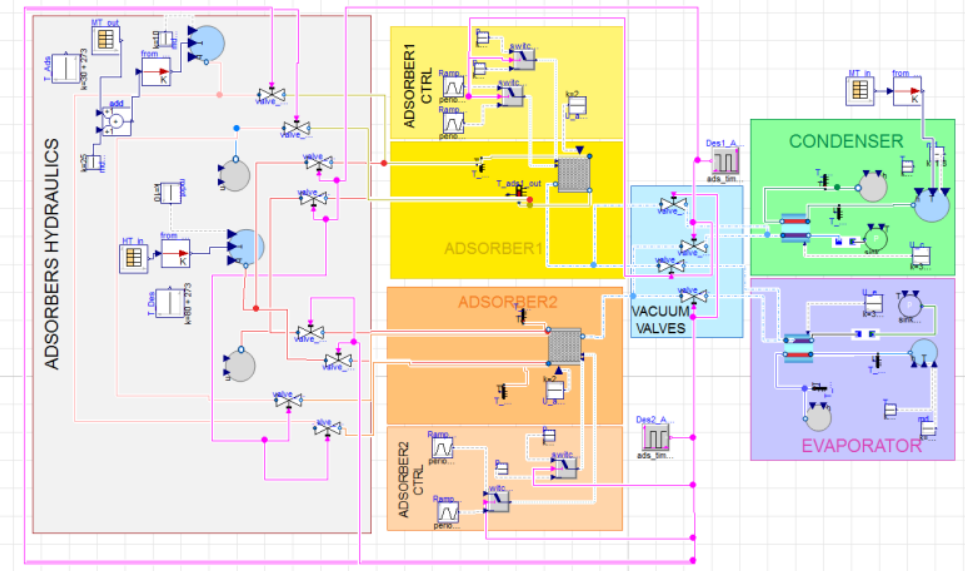

Figure 3: adsorption model implemented in Dymola.

\subsection{Model of the electric vapour compression chiller}

The dynamic model of the vapour compression unit is based on an existing heat pump model of the Thermocycle library. It consists, as shown in Figure 4, of four main elements: the compressor, the condenser, the evaporator and the expansion valve. The chosen refrigerant is R290, which is a natural refrigerant already established as an alternative to traditional refrigerant such as R410a and R407c (Sánchez et al., 2017).

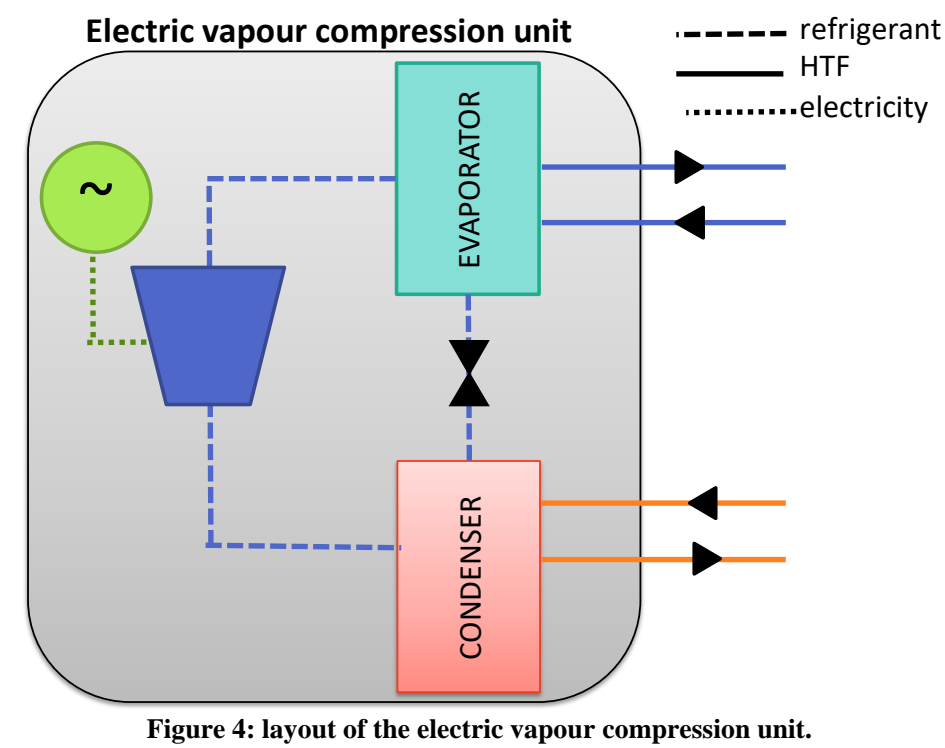

The model for the condenser and evaporator is, similarly for the evaporator and condenser of the adsorption unit, made up of two sub-models, for the heat exchange of the HTF and the equilibrium model for the phase change of the refrigerant. The heat transfer model on the HTF side is equal to the one implemented for the adsorption module.

The model for the heat transfer on the refrigerant side takes into account that it is a compressible medium. Hence, the energy and mass balance are expressed as:

$$
\begin{gathered}
\frac{d m}{d t}=\dot{m}_{\text {in }}-\dot{m}_{\text {out }}=V\left(\frac{\partial \rho}{\partial h} \frac{d h}{d t}+\frac{\partial \rho}{\partial p} \frac{d p}{d t}\right) \\
V \rho \frac{d h}{d t}-V \frac{d p}{d t}=\dot{m}_{\text {in }}\left(h_{\text {in }}-h\right)-\dot{m}_{\text {out }}\left(h_{\text {out }}-h\right)+\dot{Q}
\end{gathered}
$$

The model for the compressor is a generic model for a volumetric compressor where isentropic and volumetric efficiencies are passed as an external parameter, in order to use either a constant value or a correlation based on performance data from the producer. Thermodynamic states at the inlet and outlet of the compressor are calculated using the correlations for the refrigerant implemented in CoolProp library (Bell et al., 2014). The inlet state is defined by means of the outlet temperature of the refrigerant from the evaporator and the assumption that it is in saturated vapour conditions. The outlet conditions are calculated considering a real expansion: 


$$
h_{\text {out }}=h_{\text {in }}+\frac{h_{\text {out }, i s}-h_{\text {in }}}{\eta_{\text {is }}}
$$

The mass balance across the compressor is also implemented. Furthermore, the mass flow rate of refrigerant is a function of the rotational speed of the compressor:

$$
\dot{m}_{\text {in }}=V_{\text {swept }} \frac{r p m}{60} \eta_{v o l} \rho_{\text {in }}
$$

While the power consumption is expressed as:

$$
\dot{W}_{\text {comp }}=\frac{\dot{m}_{\text {in }}\left(h_{\text {out }}-h_{\text {in }}\right)}{\eta_{\text {vol }}}
$$

The model for the expansion valve is implemented considering that the flow rate increases linearly with the opening of the valve and that the pressure drops depend on the flow rate with a quadratic relationship.

\section{Model validation}

The developed models were integrated and the results of the simulations were compared with the experimental results of a silica gel/water unit produced by Fahrenheit and tested at CNR ITAE lab. The comparison of simulated and experimental data is presented in Figure 5. All the inlet temperatures (HT_in, MT_in and LT_in) were passed to the model of the chiller as external text files and the output temperatures (ADS1_out, ADS2_out, MT_out and LT_out) were evaluated. It is possible to notice that the simulated data closely matches the measured ones, thus demonstrating the reliability of the model and its usefulness as a sizing tool. Particularly, the fitting for the adsorbers outlet temperature was only performed during the desorption phases. The deviation between the experimental and simulated outlet temperatures of the adsorber are due to the variable cycle time of Fahrenheit unit, that is adjusted at every cycle, while a constant value was used in the simulations. Nonetheless, the model proved to be a robust and accurate method for the description of the chiller

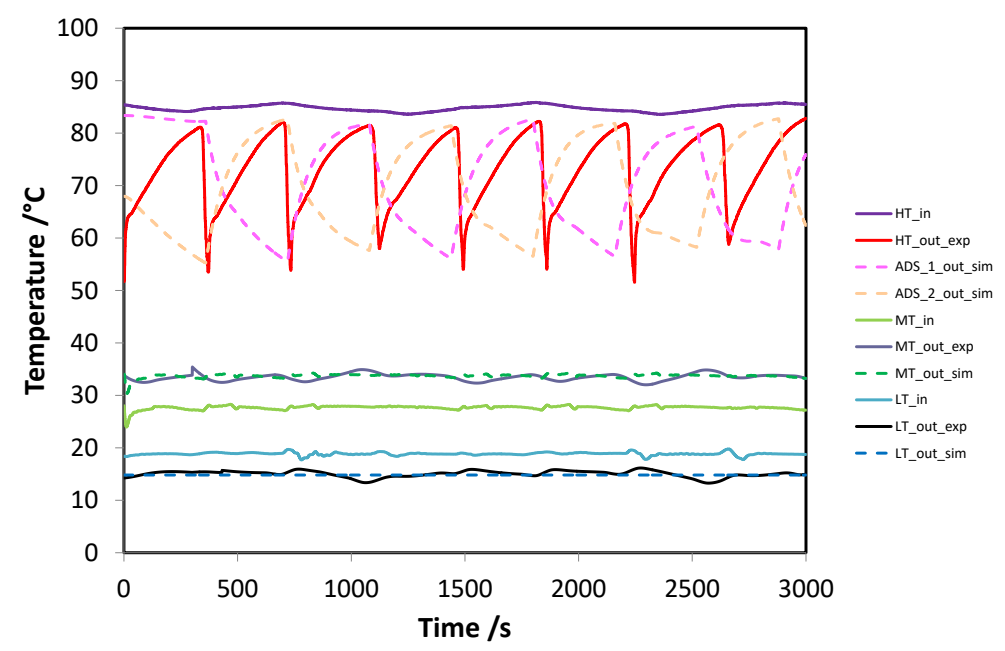

Figure 5: validation of the model by means of experimental data measured at the CNR ITAE lab.

\section{Simulation results}

Preliminary simulations were performed considering typical application for industrial sites in Barcelona, Spain, during summer operation. A daily cooling load reference profile was derived from literature data, while the ambient temperature was taken from Meteonorm library. Since a dry cooler is implemented on the condenser/adsorber side, the medium inlet temperature (MT), after the dry cooler, was considered $5 \mathrm{~K}$ higher than the ambient temperature, as represented in Figure 6.

The temperature profile of the heating source, represented by the Fresnel collector, was generated taking into account that it can be usually described, with good accuracy, by a $2^{\text {nd }}$ order polynomial evolution (Papadimitratos et al., 2016). The extreme temperatures considered for the temperature profiles are $65^{\circ} \mathrm{C}$ and $95^{\circ} \mathrm{C}$. The obtained reference profile is reported in Figure 7 


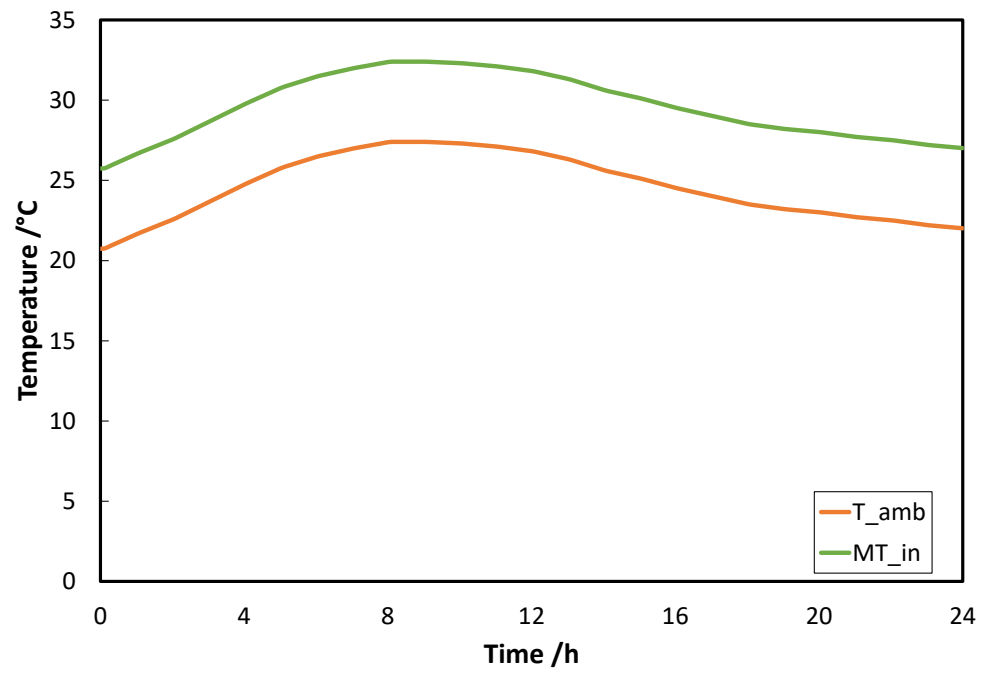

Figure 6: ambient temperature and inlet condenser temperature for Barcelona.

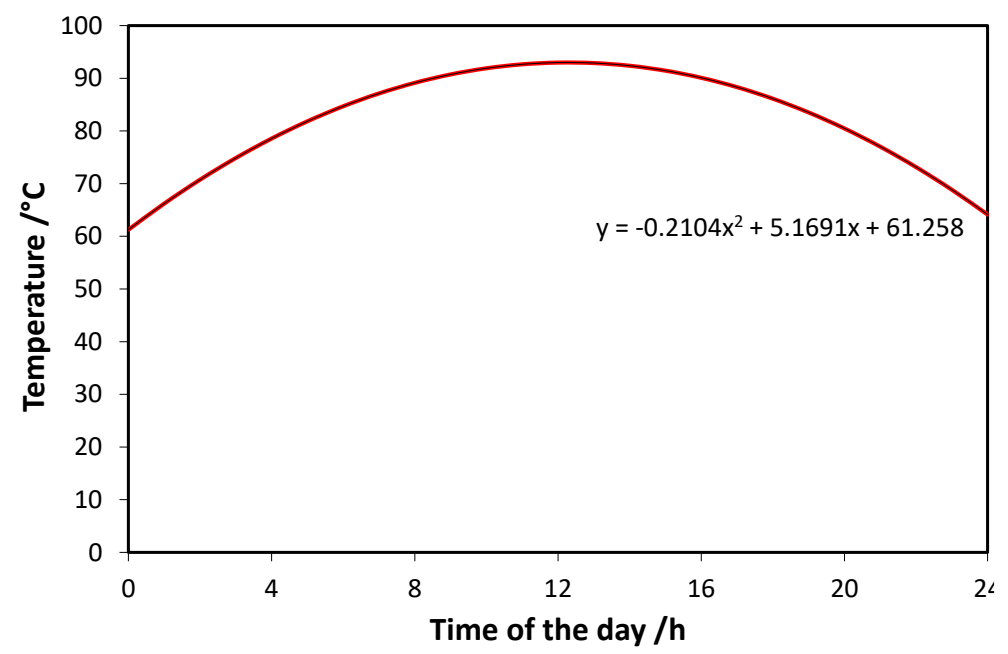

Figure 7: reference daily temperature profile provided by the Fresnel solar thermal collectors.

Starting from the boundary conditions above reported, a parametric analysis was performed to optimize the size of the adsorption unit, in order to properly operate the system, matching both the size of the solar thermal field as well as the cooling demand of the industrial site.

After this optimization phase, a complete daily simulation was performed, in order to verify the ability of the hybrid chiller in providing the needed temperature, satisfying the cooling demand. The results are presented in Figure 8 and Figure 9 that show the evolution of temperatures for the entire day, for the different hydraulic circuits entering and exiting the hybrid heat pump. It is possible to notice that the operation of the electric unit is stable and allows keeping the desired temperatures of chilled water at the evaporator. Similarly, for the optimized sizing of the adsorption chiller, the system is able to efficiently cool down the condenser of the vapour compression unit, thus confirming the reliability of the system to be realised. 


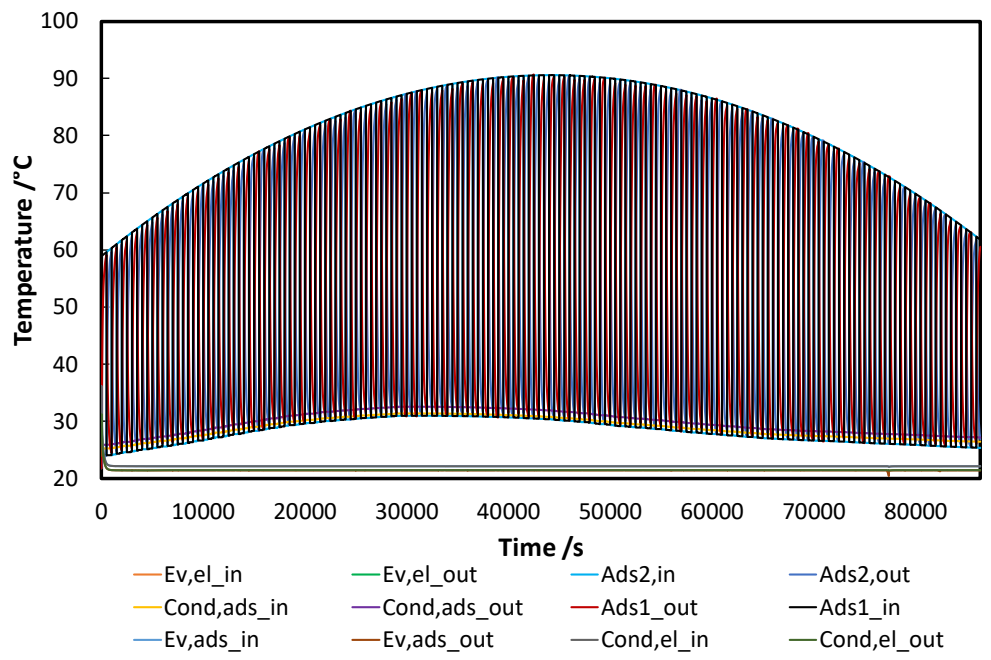

Figure 8: results of a typical daily simulation.

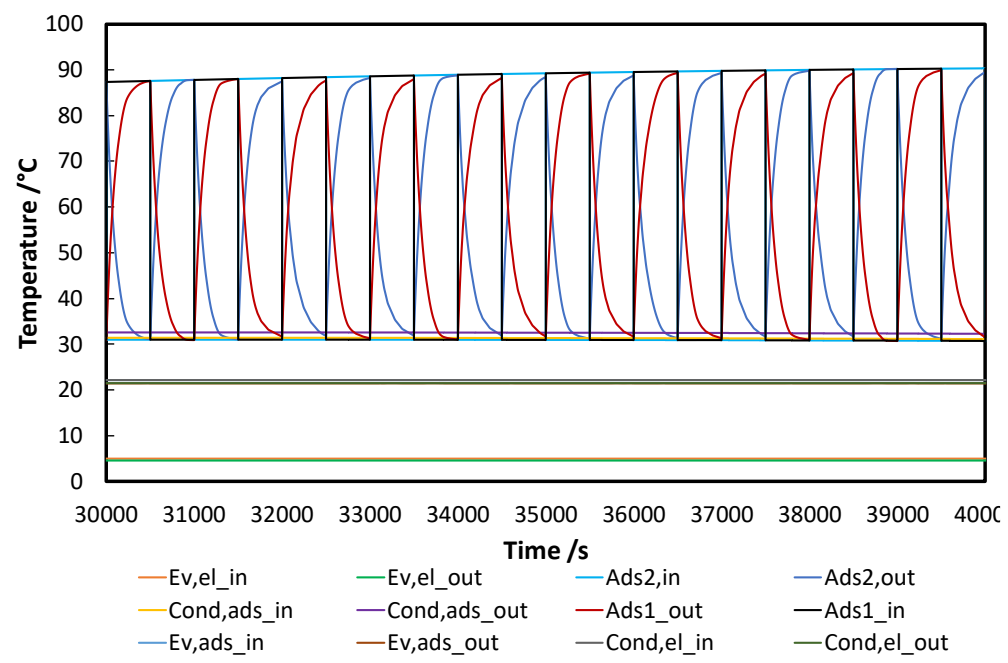

Figure 9: details of the temperature evolutions during a short time period of operation.

\section{Conclusions and future activity}

The Dymola/Modelica modeling of a cascade hybrid adsorption/vapour compression chiller driven by concentrating solar thermal collectors for industrial applications was presented. The two main sub-systems, namely, the adsorption module and the vapour compression chiller, were modelled considering heat and mass transfer propertied for each component, both on the HTF and on the refrigerant side. The implemented system was validated by means of experimental data obtained on a small-scale cascade chiller developed by Fahrenheit and tested at the CNR ITAE lab. Finally, the validated model was used to verify the ability of the cascade chiller to operate under a typical daily cooling profile in an industrial site in Spain. Starting from the developed and validated model, future activities will be oriented towards the operation optimization of the chiller, in terms of matching between thermal and electrical energy provision as well as minimization of the operation under part load conditions.

\section{Acknowledgments}

This project has received funding from the European Union's Horizon 2020 research and innovation programme under grant agreement No 792073 (HYCOOL).

\section{Nomenclature}

\begin{tabular}{|cl|cc|}
\hline $\mathrm{A}$ & Adsorption potential, $\mathrm{J} \mathrm{kg}^{-1}$ & $\dot{\mathrm{W}}$ & $\begin{array}{c}\text { Compressor work, } \mathrm{kW} \\
\text { Greek letters }\end{array}$ \\
$\mathrm{b}$ & Equilibrium constant, $\mathrm{kg} \mathrm{J}^{-1}$ & & Heat transfer coefficient, $\mathrm{W} \mathrm{m}^{-2} \mathrm{~K}^{-1}$ \\
$\mathrm{c}_{\mathrm{p}}$ & Specific heat, $\mathrm{J} \mathrm{kg}^{-1} \mathrm{~K}^{-1}$ & $\alpha$ & Efficiency \\
$\mathrm{D}$ & Diffusion coefficient, $\mathrm{m}^{2} \mathrm{~s}^{-1}$ & $\eta$ &
\end{tabular}




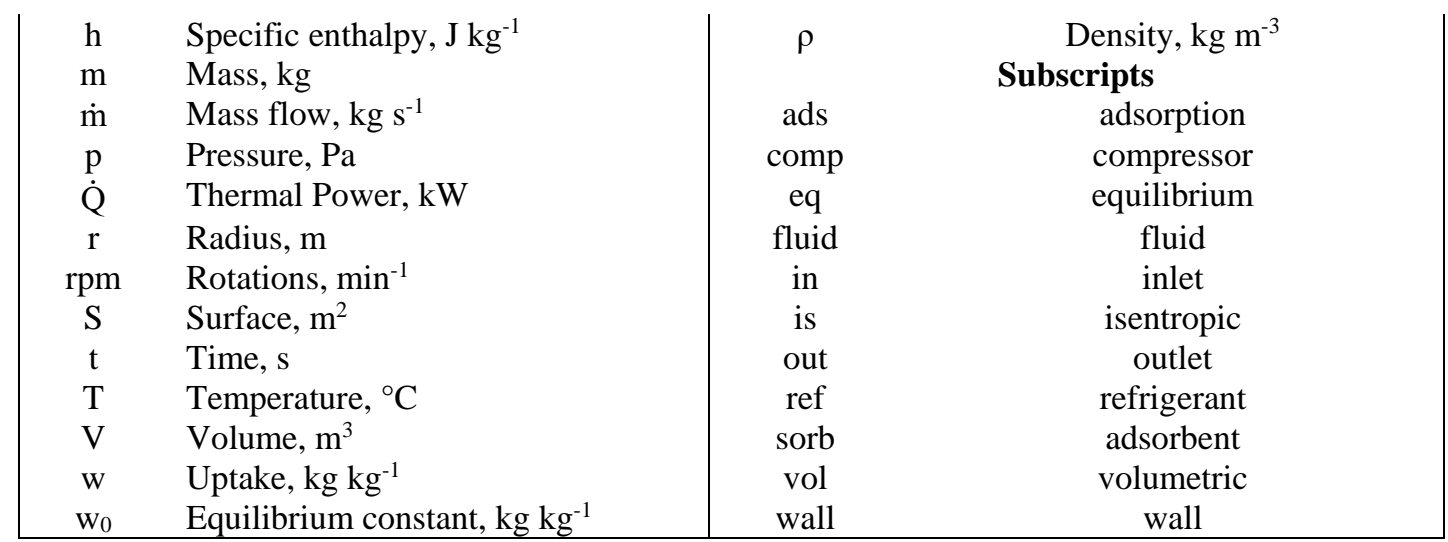

\section{References}

Bales, C., Gantenbein, P., Hauer, A., Henning, H.-M., Jaenig, D., Kerskes, H., ..., 2005. Thermal properties of materials for thermo-chemical storage of solar heat.

Bell, I.H., Wronski, J., Quoilin, S., Lemort, V., 2014. Pure and Pseudo-pure Fluid Thermophysical Property Evaluation and the Open-Source Thermophysical Property Library CoolProp. Ind. Eng. Chem. Res. 53, 2498-2508. https://doi.org/10.1021/ie4033999

Dubinin, M.M., Astakhov, V.A., 1971. Development of the concepts of volume filling of micropores in the adsorption of gases and vapors by microporous adsorbents - Communication 2. General bases of the theory of adsorption of gases and vapors on zeolites. Bull. Acad. Sci. USSR Div. Chem. Sci. 20, 8-12. https://doi.org/10.1007/BF00849308

El-Sharkawy, I.I., 2011. On the linear driving force approximation for adsorption cooling applications. Int. J. Refrig. 34, 667-673. https://doi.org/10.1016/J.IJREFRIG.2010.12.006

Farjana, S.H., Huda, N., Mahmud, M.A.P., Saidur, R., 2018. Solar process heat in industrial systems - A global review. Renew. Sustain. Energy Rev. 82, 2270-2286. https://doi.org/10.1016/J.RSER.2017.08.065

HyCool, 2018. HyCool [WWW Document].

Lanzerath, F., Bau, U., Seiler, J., Bardow, A., Bardow, E., 2015. Optimal design of adsorption chillers based on a validated dynamic object-oriented model. Sci. Technol. Built Environ. 21, 248-257. https://doi.org/10.1080/10789669.2014.990337

Murray, C., Quiñones, G., Cortés, F., Escobar, R., Cardemil, J.M., 2016. Solar Assisted Absorption Machine for the Fermentation Cooling and Maceration Heating Processes in the Winemaking Industry. Energy Procedia 91, 805-814. https://doi.org/10.1016/J.EGYPRO.2016.06.247

Papadimitratos, A., Sobhansarbandi, S., Pozdin, V., Zakhidov, A., Hassanipour, F., 2016. Evacuated tube solar collectors integrated with phase change materials. Sol. Energy 129, 10-19. https://doi.org/10.1016/J.SOLENER.2015.12.040

Quoilin, S., Desideri, A., Wronski, J., Bell, I., Lemort, V., 2014. ThermoCycle: A Modelica library for the simulation of thermodynamic systems, in: Proceedings of the 10th International Modelica Conference. Lund,Sweden. https://doi.org/10.3384/ECP14096683

Sánchez, D., Cabello, R., Llopis, R., Arauzo, I., Catalán-Gil, J., Torrella, E., 2017. Energy performance evaluation of R1234yf, R1234ze(E), R600a, R290 and R152a as low-GWP R134a alternatives. Int. J. Refrig. 74, 269282. https://doi.org/10.1016/J.IJREFRIG.2016.09.020

Sapienza, A., Velte, A., Girnik, I., Frazzica, A., Füldner, G., Schnabel, L., Aristov, Y., 2017. "Water - Silica Siogel" working pair for adsorption chillers: Adsorption equilibrium and dynamics. Renew. Energy 110, 4046. https://doi.org/10.1016/J.RENENE.2016.09.065

Vasta, S., Palomba, V., La Rosa, D., Mittelbach, W., 2018. Adsorption-compression cascade cycles: An experimental study. Energy Convers. Manag. 156, 365-375. https://doi.org/10.1016/j.enconman.2017.11.061

Werner, S., 2016. European space cooling demands. Energy 110, 148-156. https://doi.org/10.1016/J.ENERGY.2015.11.028 